for relevant information in formats useful to informed decision-making. There is much to do in that regard.

References

1. Powlson, D. S. et al. Nature Clim. Change 4, 678-683 (2014)

2. Neufeldt, H., Adhya, T. K., Coulibaly, J. Y., Kissinger, G. \& Pan, G. in The Emissions Gap Report 2013 Ch.4 (United Nations Environment Programme, 2013).
3. Smith, P. et al. in Climate Change 2007: Mitigation of Climate Change Ch. 8 (IPCC, Cambridge Univ. Press, 2007).

4. Golub, A., Hertel, T., Lee, H-L., Rose, S. \& Sohngen, B. Resour. Energy Econ. 31, 299-319 (2009).

5. Derpsch, R., Friedrich, T., Kassam, A. \& Hongwen, L. Int. J. Agric. Biol. Eng. 3, 1-25 (2010).

Henry Neufeldt ${ }^{1 \star}$, Gabrielle Kissinger ${ }^{2}$ and Joseph Alcamo ${ }^{3}$
'World Agroforestry Centre (ICRAF), United Nations Avenue, 00100 Nairobi, Kenya. ${ }^{2}$ Lexeme Consulting, Vancouver, British Columbia, Canada. ${ }^{3}$ Center for Environmental Systems Research, University of Kassel, Wilhelmshöher Allee 47, 34117 Kassel, Germany. *e-mail: h.neufeldt@cgiar.org

\title{
Reply to 'No-till agriculture and climate change mitigation'
}

Powlson et al. reply - In our recent Perspective $^{1}$, we concluded that no-till agriculture offered only limited potential for mitigating climate change through soil carbon $(\mathrm{C})$ sequestration, in contrast to the claims made in the agriculture chapter of the 2013 UNEP Emissions Gap Report ${ }^{2}$. The authors of the UNEP report disagree with our conclusion and we are happy to respond to their comments ${ }^{3}$. They are correct that we concentrated totally on no-till rather than other agricultural practices as a means of mitigating climate change. This was deliberate because current uptake of notill - and its probable rate of adoption in the medium term - is far greater than for the other practices mentioned, such as agroforestry and biochar applications to soil. And we have no disagreement with their comments on climate change mitigation through improved water and nutrient management and reduced use of fossil fuels - in fact, alterations to water and nutrient management are probably the most effective approaches in all agricultural systems, not only rice production.

We agree with Neufeldt et al. ${ }^{3}$ that estimating soil $\mathrm{C}$ accumulation following adoption of no-till using a 'bottom-up' approach is, in principle, preferable to the 'top-down' method we used. In their Correspondence, Neufeldt et al. ${ }^{3}$ accomplish bottom-up estimations of avoided emissions for specific countries by multiplying the area under no-till by a climate-relevant value for the annual rate of increase in soil organic $\mathrm{C}$ under the practice. They acknowledge the considerable uncertainty in rates of accumulation under no-till: for example, their estimate for Australia ranges from over $400 \mathrm{MtCO}_{2}$ e saved from past notill adoption to additional emissions of over $200 \mathrm{MtCO}_{2} \mathrm{e}$ compared with conventional cultivation ${ }^{3}$. In the face of such uncertainty the strong promotion of no-till as an effective means of climate change mitigation in the UNEP Emissions Gap Report ${ }^{2}$ looks distinctly unjustified.
In our Perspective ${ }^{1}$ we explained the numerous reasons why measurements of soil C change under no-till are almost always overestimates. These errors will have influenced the published values such as those of Smith et al. ${ }^{4}$ and used by Neufeldt et al. ${ }^{3}$, yet they continue to ignore them. They further ignore the findings from a large body of experimental data that we cited ${ }^{1}$, showing either small rates of soil $\mathrm{C}$ accumulation under no-till or no effect in a substantial number of cases.

\section{No-till agriculture can deliver significant benefits for farmers and sustainability in many situations: reduced GHG emissions \\ are a small but important additional benefit}

Neufeldt et al. arrive at their estimations of future avoided emissions by assuming that historic rates of adoption of no-till over the past 2-34 years will continue indefinitely ${ }^{3}$. This assumption is highly questionable because in countries covering large areas where no-till is already widely adopted (for example, Australia, USA, Canada, Brazil, Argentina) the change in tillage practice will already have occurred in the most suitable situations.

A recent theoretical study ${ }^{5}$ came to the conclusion that $\mathrm{C}$ sequestration in agricultural soils through changed management practices, including notill, could provide "only a humble contribution to solving the climate problem of the coming decades". Of course, even small contributions are welcome - put colloquially, every little helps. But it is important that scientists are realistic when making statements about the relative magnitudes of mitigation achievable through different options. This is essential for assisting policymakers to arrive at evidence-based decisions on the prioritization of possible options. A recent meta-analysis ${ }^{6}$ drew attention to the risk of crop yield losses in many environments if no-till is not accompanied by crop residue retention and/or crop diversification - together with no-till these practices are elements of 'conservation agriculture' so, from the viewpoint of food security and farmer livelihoods, caution is needed in proposing no-till alone as done by Neufeldt and colleagues ${ }^{2,3}$.

We see no reason to alter the conclusion from our original Perspective1: "No-till agriculture can deliver significant benefits for farmers and sustainability in many (though not all) situations: reduced GHG emissions are a small but important additional benefit, not the key policy driver for its adoption."

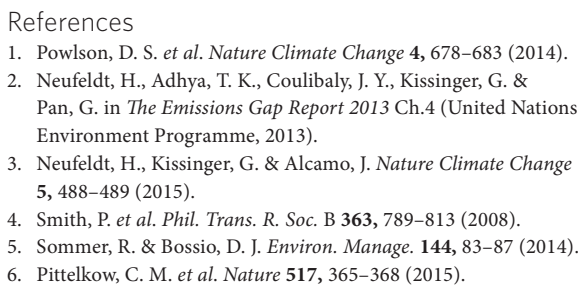

3. Neufeldt, H., Kissinger, G. \& Alcamo, J. Nature Climate Change 5, 488-489 (2015)

4. Smith, P. et al. Phil. Trans. R. Soc. B 363, 789-813 (2008).

5. Sommer, R. \& Bossio, D. J. Environ. Manage. 144, 83-87 (2014).

6. Pittelkow, C. M. et al. Nature 517, 365-368 (2015).

David S. Powlson ${ }^{1 \star}$, Clare M. Stirling ${ }^{2}$, M. L. Jat ${ }^{3}$, Bruno G. Gerard², Cheryl A. Palm4, Pedro A. Sanchez ${ }^{4}$ and Kenneth G. Cassman ${ }^{5}$ 'Department of Sustainable Soils \& Grassland Systems, Rothamsted Research, West Common, Harpenden, Hertfordshire AL5 2JQ, UK. ${ }^{2}$ The International Maize and Wheat Improvement Center (CIMMYT), Global Conservation Agriculture Program, Mexico City 6-641 06600, Mexico.

${ }^{3}$ The International Maize and Wheat Improvement Center (CIMMYT), India Office, NASC Complex, Pusa, New Delhi, New Delhi 110012, India. ${ }^{4}$ Agriculture and Food Security Center, Earth Institute, Columbia University, 61 Route 9W, Lamont Hall, Palisades, New York 10964, USA. ${ }^{5}$ Department of Agronomy and Horticulture, University of NebraskaLincoln, Lincoln, Nebraska 68583-0915, USA. *e-mail: david.powlson@rothamsted.ac.uk 